\title{
The Functionality of Fiber Bragg Grating Sensor Compared to that of Foil Gauge
}

\author{
Bashir Ahmed Tahir, Jalil Ali and Rosly Abdul Rahman \\ Fiber Optics and Photonics Research Laboratory, Department of Physics, Faculty of Science \\ University Technology Malaysia, Johor, Malaysia
}

\begin{abstract}
Technology such as Fiber Bragg Grating (FBG) sensors are widely accepted in almost all industries. FBG are being investigated for their applicability in other markets such as smart structures. Fiber optic sensors can also be used in many different applications. Fiber optic sensors are available in several types; among them, the Bragg grating sensor is being studied in this research. For this research work, the main focus was the use of fiber Bragg grating sensors for measuring strain. The key objective of this research; to determine the functionality of fiber Bragg grating sensors compared to that of conventional foil gauges. Fiber Bragg grating sensors were chosen for this research because they have a high potential for various uses in the monitoring of smart structures. The major incentives for this type of research are the current deterioration of civil structures in west Malaysia. The laboratory tests are being reported in this research work including tests of steel straps and an aluminum test specimen. In all the tests, strain was measured using the fiber Bragg grating sensors and compared to values from a conventional foil gauge. The results are being discussed in details. It was inferred that the use of fiber optic technology for the monitoring of civil structures is very promising and the future is sure to bring further advancements and improvements.
\end{abstract}

Key words: Fiber Bragg grating sensor, conventional foil gauge, smart structures, laboratory tests

\section{INTRODUCTION}

New developments are happening daily in all areas of science. As part of the 'Information Age' we "generate, process, store, display and transmit information in ever increasing amounts. Sensing and measuring is one aspect of information generation that will become an increasingly important activity in the coming years ${ }^{[1]}$. More importantly, advances in the field of information technology have allowed people to keep up to date in their own field, as well as many other areas of science and technology. The increase in information generation has allowed for technology transfer and networking between science and engineering disciplines, which may have never worked together before ${ }^{[2]}$.

For several years now, civil engineers have been collaborating with researchers in the field of optoelectronics, in efforts to develop fiber optic sensing and monitoring systems for civil engineering structures. Optoelectronics are the core of the telecommunications industry and are an important part of sensing in the aerospace industry. In the last ten to twenty years, optoelectronic technology has emerged in the fields of civil engineering, manufacturing and biomedicine, etc., in products such as fiber optic sensors ${ }^{[3]}$.

Monitoring and inspection of in-service structures is necessary to determine their condition and to prevent unsafe conditions or catastrophic failure. Undetected defects can result in a structure, which requires expensive repair, or early replacement. Prediction of failure and detecting defects is especially useful in structures such as dams, bridges and nuclear waste containment vessels; facilities where failure presents large safety concerns. Currently, most structures are inspected on a set schedule and the techniques for determining the state of the structure can be expensive, labour intensive and time consuming. In some states of Malaysia, such as Johor, the condition of a bridge is established almost entirely by visual inspection. More rigorous inspections can be carried out, but they are very costly and time consuming. The ideal approach would be to develop a bridge inspection system, which is much less subjective ${ }^{[4,5]}$.

There are several goals that should be met when developing a new sensing system. The system must be suitable for both laboratory and field applications and the overall cost of the system should not be prohibitive. The instrumentation used for monitoring has many requirements to satisfy. It should be easy to use, cost effective, durable and able to operate in extreme weather conditions and provide for monitoring from a remote location. Many advantages can be realized by using sensors to instrument a structure for long-term remote monitoring. There can be long-term savings in labour, money and time; problems can be detected before they become too severe to repair easily; and the software used with the monitoring system can be

Corresponding Author: Bashir Ahmed Tahir, Fiber Optics and Photonics Research Laboratory, Department of Physics, Faculty of Science, University Technology, Malaysia, Johor, Malaysia, Tel: +607-5534110 Fax: +607-5566161 
programmed to set off alarms when values of load or stress become critical. Long term monitoring can also provide insight into the behavior of a structure during construction and while it is in service. This feedback can assist in the development of more efficient and economic designs and design codes ${ }^{[6]}$.

With fiber optic sensors other advantages can be realized. Fiber optic sensors are versatile in that they can be used to monitor many different parameters such as strain, temperature, vibration, deformation and acceleration. Optical sensors have other advantages over conventional sensors including: greater sensitivity, electrical passiveness, freedom from electromagnetic interference, wide dynamic range and both point and distributed configuration ${ }^{[7]}$. Bragg grating sensors in particular, are appealing because of their multiplexing capabilities; the ability to merging data from several channels into 1 channel $^{[8]}$.

The future vision for the use of fiber optic sensors in civil engineering includes the development of 'smart structures'. Much of the work done in the area of smart structures was initiated by the United States military in the early 1980 ' $\mathrm{s}^{[1]}$. Smart structures are defined in many different ways. A simple definition is that a smart structure is one, which "possesses a structurally integrated sensor system for determining its state ${ }^{[9]}$. Several other terms used to describe types of smart structure, which have been developed include, adaptive smart structures, passive smart structures, intelligent structures and sensing structures. Each type performs a different function or set of functions; some structures may only sense their state, while others may be capable of adapting based on the feedback obtained. For example, an intelligent structure could sense the environment and state of the structure itself, process the sensed information, make decisions for reaction and then react to the information ${ }^{[10]}$.

A series of laboratory tests and other relevant field work was carried out in the process of this research. Test data has been recorded for 3 Bragg grating sensors in total. Laboratory testing was performed on two steel straps and an aluminum test specimen. All of the test specimens were instrumented with bondable Bragg grating sensors and foil gauges for comparison.

\section{MATERIALS AND METHODS}

One goal in the field of civil structures is for all monitoring of existing structures to be done in a nondestructive manner. It is very advantageous to be able to evaluate the structural integrity of a bridge or building and examine the critical areas, without having to significantly modify the structure. One of the most common methods of non-destructive testing is to apply sensor to a structure, by bonding or welding and then take readings from the sensor while the structure is in service, or during a special test. In case of electrical strain gauge, the Data Logger was the main instrument using for the reading of strain values and in case of fiber optic sensor the Optical Spectrum Analyzer was the main instrument using for the monitoring of Bragg wavelength shift, which was varying due to change of load. The value of strain was calculated against each value of load/ wavelength shift using following equation $^{[11]}$.

$\varepsilon=\Delta \lambda_{\mathrm{B}} /(1-\mathrm{Pe}) \lambda_{\mathrm{B}}$

Electrical strain gauges: There are many types of gauges available for measuring strain. The most common is foil gauges also know as electrical resistance gauges. Typically a foil gauge is applied to the surface of structure or object of interest. More recently, gauges such as the vibrating wire gauge and embedment foil gauge have been developed for embedment in concrete.

Principle of operation: The conventional foil gauge, or resistive strain gauge, works on the principle that the electrical resistance of the metal in the gauges changes in proportional to the mechanical strain. These gauges have been used for many years and have a long history to attest to their functionality. The wire used is simple to splice and connect. Conventional foil gauges are available for surface application in both bondable and weld able forms. The bondable gauges are sufficient for laboratory use but weldable gauges are preferred for field application. In the field, however, foil gauges typically only have a working life of two years due to corrosion of the metal foil. The cost of a conventional bondable foil gauges ranges from \$25-40, depending on size. The strain gauge was connected with Data Logger, which was used to read the value of strain and is shown in Fig. 1.

Optical spectrum analyzer: The MS9710B Optical Spectrum Analyzer is a diffraction grating spectrum analyzer. This rugged, compact unit is ideal for field as well as laboratory application, including:

* Characterization of LEDs, Fabry-Perot LDs and DFB LDs

* EDFA Noise Figure and Gain

* Polarization MODE Dispersion measurements

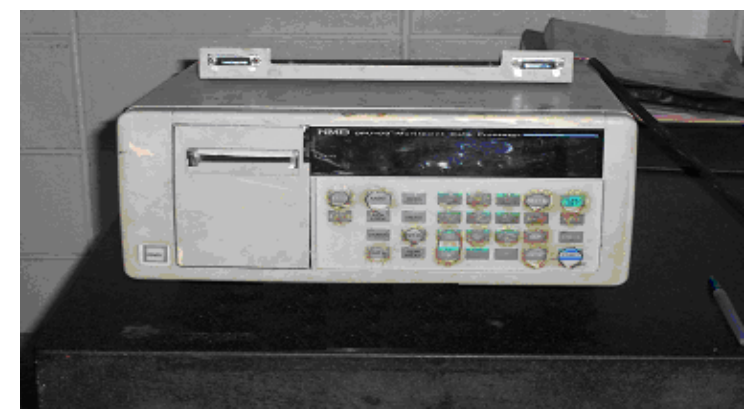

Fig. 1: Data logger 


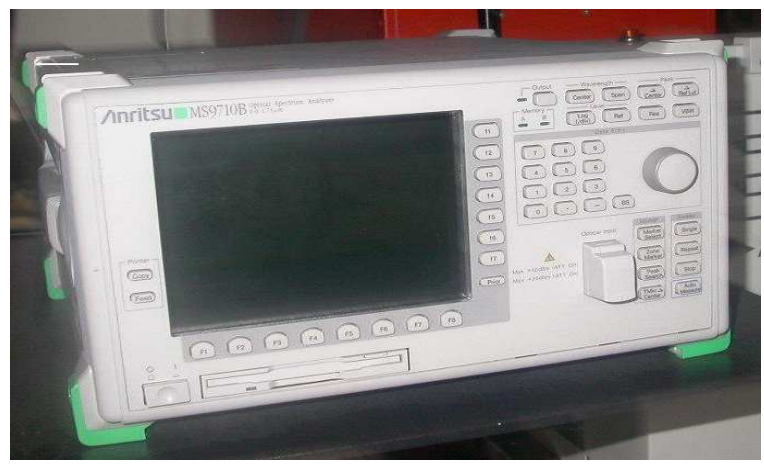

Fig. 2: Optical spectrum analyzer

* Transmission characteristics of passive elements such as isolators and filters

* Optical internal light source for calibrating wavelength

* Tracking measurement with MG9637 / MG 9638 Tunable Laser Source

Optical levels in the wavelength range from 600 to $700 \mathrm{~nm}$ can be measured with a maximum resolution of $0.07 \mathrm{~nm}$. Settings such as the resolution, averaging, smoothing and number of measurements points, etc., can be set according to the measurement purpose. In addition, peaks and troughs can be detected, the spectrum can be analyzed and the spectrum width and SMSR, etc., can be found. The measured data and waveform can be saved to floppy disk in the MS9710B data format. The text and bitmapped files can be easily incorporated into popular word-processor and spreadsheet applications and is shown in Fig. 2.

Principle of operation: The Optical spectrum analyzer works by detecting changes in the wavelength reflected by the Bragg gratings on a sensor; a change of strain in the fiber induces a shift in reflected wavelength. Light at the Bragg wavelength is reflected, while other wavelength transmitted. Absolute measurements are possible in the sense that the center wavelength of the grating is obtained in absolute terms. The signal received from the grating sensor is immune to signal intensity fluctuations which may arise from environmental and operating conditions.

Optical Spectrum Analyzer was the instrument, which was used for reading transmission and reflection spectrum. Hence from the transmission spectrum, the Bragg wavelength shift was monitored and as a sample one transmission spectrum is shown in Fig. 3.

Experimental work: The experimental work, consist of measuring of stain by electrical strain gauge and fiber Bragg grating sensor when bonded on the surface of Steel Straps and Aluminum Specimen. Firstly, the tests in compression and in tension were performed on Steel Strap 1 and Steel Strap 2. Secondly, the tensile tests were completed on an Aluminum test Specimen.

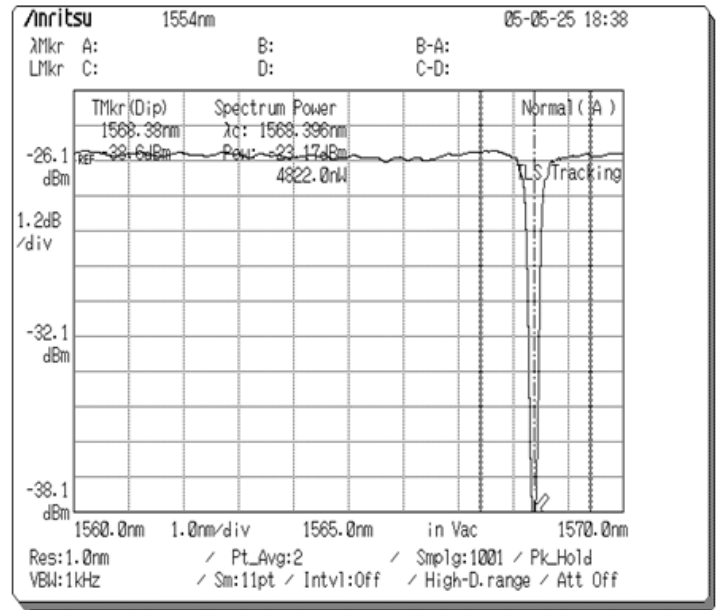

Fig. 3: Transmission spectrum

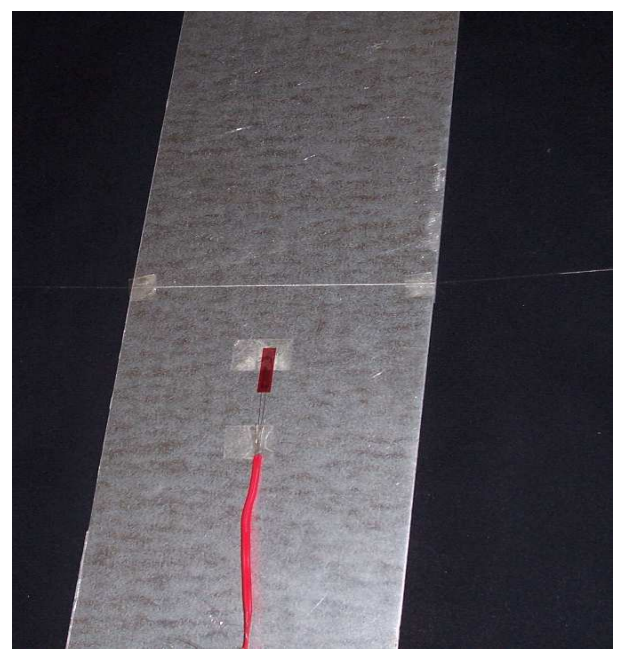

a)

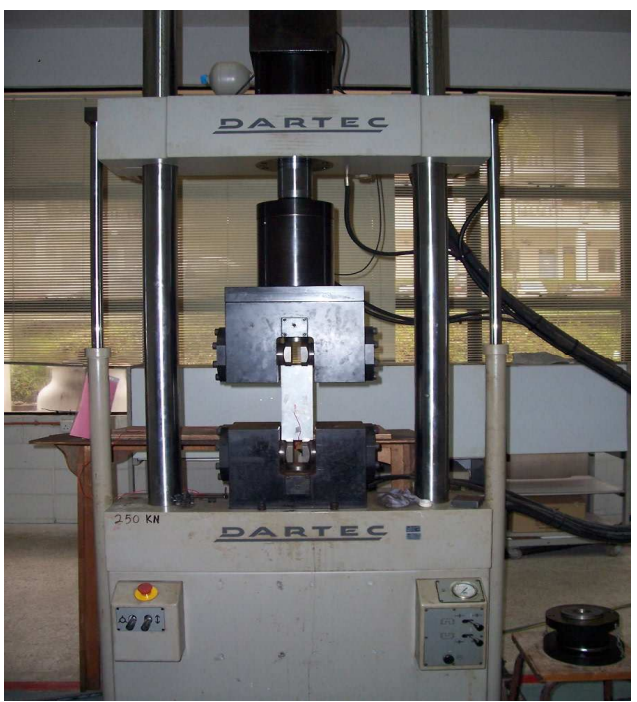

b)

Fig. 4a: Fiber optic sensor and foil gauge bonded to steel strap (b) load instron machine for compression \& tensile testing 


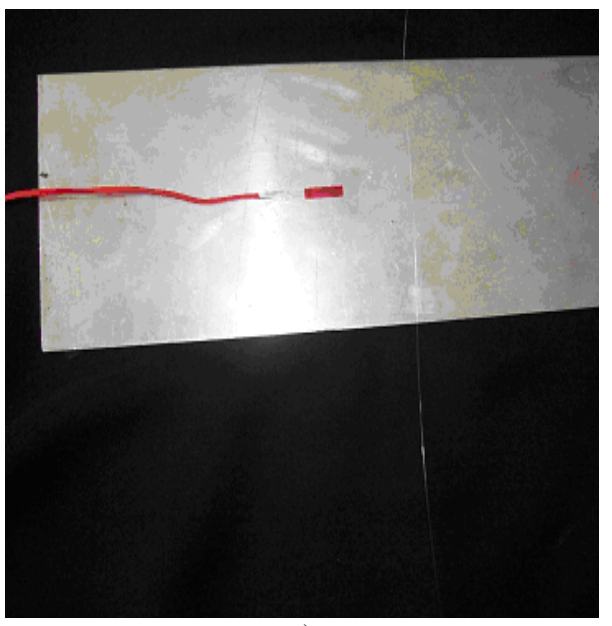

a)

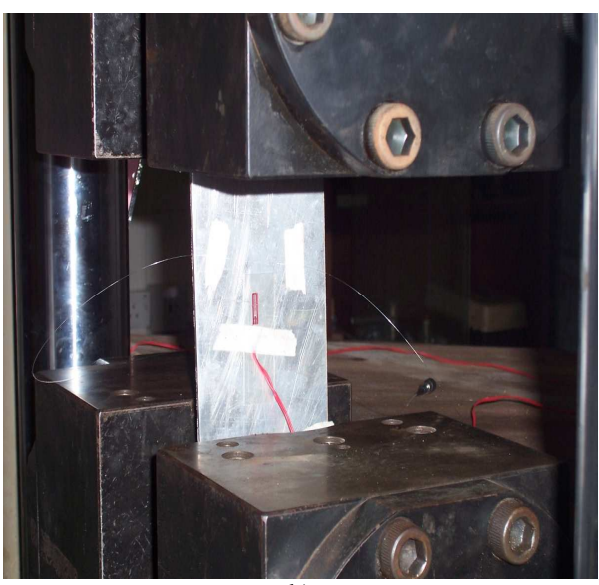

b)

Fig. 5a: Fiber optic sensor and foil gauge bonded to aluminum specimen (b) load instron machine for tensile testing

Table 1: Comparison of results to theoretical values for testing of straps

\begin{tabular}{lllll}
\hline & Strap 1 & & Strap 2 & \\
& --------------- & -------------- \\
& Fiber optic & Foil & Fiber optic & Foil \\
& Sensor & gauge & sensor & gauge \\
\hline Compression & $-0.5 \%$ & $-7.2 \%$ & $-2.2 \%$ & $-3.1 \%$ \\
Tension & $-0.9 \%$ & $-10.7 \%$ & $-1.6 \%$ & $-6.7 \%$ \\
\hline
\end{tabular}

Steel straps specimen: Testing of two steel straps were completed in the Civil Structures Laboratory of the University Technology Malaysia. The straps are identified as Strap 1 and Strap 2, were equipped with an electrical strain gauge and a fiber optic Bragg grating sensor as shown in Fig. 4a. The Straps were tested a total of six times each; three times with the fiber Bragg grating sensor bonded on one side and an electrical strain gauge bonded on other side of Steel Straps (in compression) and three times with the fiber Bragg grating sensor and electrical strain gauge bonded in the middle of Steel Straps (in tension). Compression and Tensile testing of steel straps were performed using the Load Instron machine as shown in Fig. 4b.

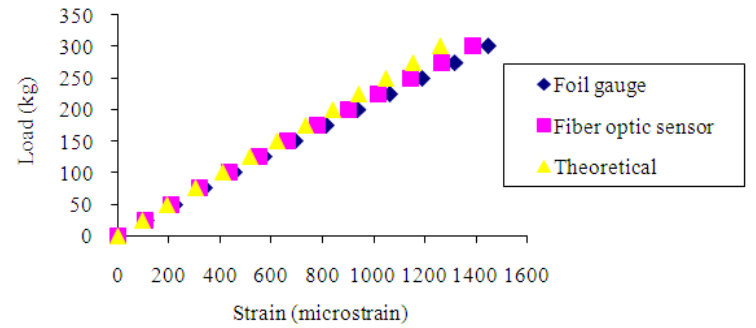

Fig. 6: Load vs. Strain of steel strap 1, fiber optic in compression

Aluminum test specimen: The Aluminum test Specimen was equipped with a fiber Bragg grating sensor and a foil gauge. The fiber Bragg grating sensor and foil gauge bonded in the middle of Aluminum Specimen as shown in Fig. 5a. Tensile tests were performed on the Aluminum specimen using the Load Instron Universal testing machine in the Material Testing Lab and are shown in Fig. 5b. The Aluminum Specimen was tested four times.

\section{RESULTS AND DISCUSSION}

All laboratory testing were performed in the Fiber Optic and Photonics Research Laboratory of Physics Department and Structure Laboratory of Civil Engineering Department of the University Technology Malaysia. Laboratory investigations included testing of two steel straps (in tension/in compression) and aluminum test specimen (in tension).

The results show that the foil gauge data correlates better with the theoretical calculation than the fiber optic sensor values. The Bragg grating sensors performed slightly better when tested in compression than in tension. A summary of the results is shown in Table 1. A typical graph of the results is shown in Fig. 6. It should be noted that by visual inspection, the fiber optic gauge on Strap 1 was applied to the steel strap at approximately 3 degrees off the longitudinal axis. This could explain why the data from Strap 2 is better than that from Strap 1. Also, the foil gauge on Strap 2 had a very small segment, which was not bonded, which would account for the higher discrepancy in the foil gauge results for that strap.

The fiber optic sensor on Strap 2 gave inconsistent results with a 3 percent higher maximum strain than the foil gauge in the first test and with a 6 percent lowers maximum strain in the second test. The Bragg grating sensor on Strap 2 did however perform better than the sensor on Strap 1, which gave a maximum strain 15 percent lower than the foil gauge.

Based on the results of the steel strap testing, the performance of the Optical Spectrum Analyzer and the fiber optic sensor was called into question. 
Table 2: Maximum strain values for gauges on aluminum test specimen, under Tensile Loading of $17 \mathrm{KN}$

\begin{tabular}{llll}
\hline $\begin{array}{l}\text { Trail Fiber } \\
\text { No. }\end{array}$ & $\begin{array}{l}\text { Foil } \\
\text { optic sensor }\end{array}$ & $\begin{array}{l}\text { Percent } \\
\text { gauge }\end{array}$ & Difference \\
\hline Trail 1 & 1578 & 1713 & 7.8 \\
Trail 2 & 1580 & 1737 & 8.9 \\
Trail 3 & 1569 & 1741 & 9.9 \\
Trail 4 & 1586 & 1738 & 8.6 \\
Average & 1579 & 1733 & 8.9 \\
\hline
\end{tabular}

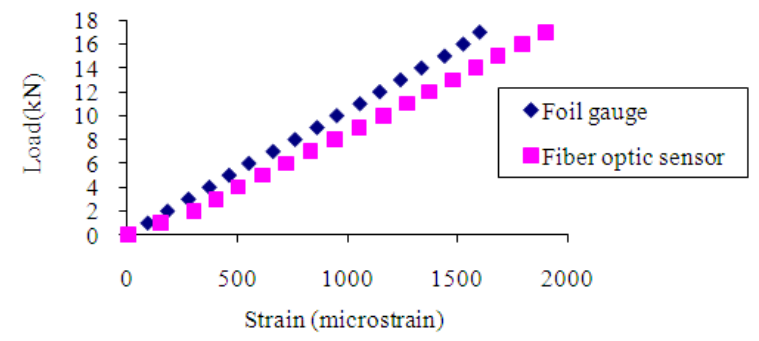

Fig. 7: Load vs. strain for aluminum test specimen, trial 1

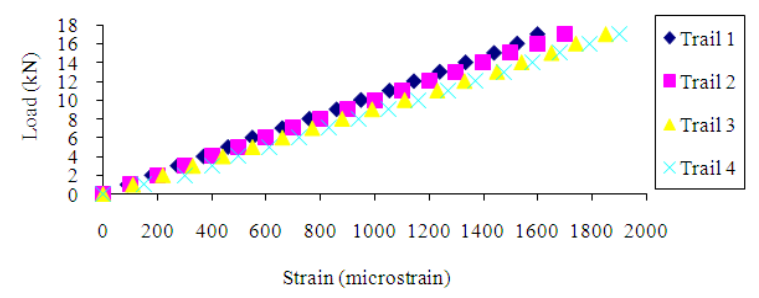

Fig. 8: Load vs. strain of fiber optic sensor on aluminum test specimen over four trails

A calibrated aluminum tensile specimen was supplied by the sensor manufacturer to determine which of the two components, the instrument or the sensors, was the cause of the poor performance. The specimen had a fiber optic sensor and a foil gauge bonded in the middle of aluminum specimen.

Tensile tests were performed on the aluminum specimen using the Load Instron Universal Testing Machine in the Materials Testing Lab. The maximum strain values indicated by the foil gauge were between 7.8 and 9.9 percent lower than the values from the fiber optic sensor. The average difference over four trials was 8.7 percent. The results from trial 1 are shown in Fig. 7. The results are also summarized in Table 2.

The discrepancy between the foil gauge and fiber optic values could have been due in part to the fact that a specimen undergoes a minimal amount of bending in a tensile test. The bending results in one side of the test specimen experiencing slightly higher or lowers strain than the other. Overall, the test results were not as good as the results of the tests performed on the specimen by ElecttoPhotonics in their laboratory. The Bragg grating sensor did perform quite consistently over the four trials, as seen in Fig. 8, which suggests that the fiber optic sensor was functioning well. This suggested that there was a problem with the Data Logger and the instrument was therefore returned for repair.

\section{CONCLUSION}

The use of fiber optic technology for the monitoring of smart structures is very promising and the future is sure to bring further advancements and improvements. Because this is a rather new technology and few people have experience with Bragg grating sensors, is of utmost importance to detail the practical problems encountered during the implementation and installation of the sensors. The overall results of the research have provided great encouragement for the continued study of the development and use of fiber optic sensors for monitoring of smart structures.

The Bragg grating sensors themselves adapt well to use on, "smart structure". The tests discussed in this research show a reasonable correlation between the strain values obtained from the fiber optic sensors and those obtained from conventional foil gauges; from a maximum difference of seven percent for a properly applied gauge to as close as 0.9 percent for a Bragg grating sensor. The factor that most limits the use of foil gauge is the instruments used with them. The Data Logger that was used in these tests is one of the earlier models. It is anticipated that improvements will be achieved with other models and the development of a demodulator chip. The development of the optoelectronic demodulator chip will be a significant advancement in the use of fiber optic sensors in monitoring networks resulting in cost savings and a simplification of the overall system.

\section{REFERENCES}

1. Forrest, S., L.A. Coldren, S. Esener, D. Keck, F. Leonberger, G.R. Saxonhouse and P.W. Shumate, 1996. Optoelectronics in Japan and the United States. Japanes Technology Evaluation Center, Panel report.

2. Zdunek, A.D., D.W. Prine, Z. LI, e. Landis and S. Shah, 1995. Early detection of steel rebar corrosion by Acoustic Emission monitoring. CORROSION95, The NACE Intl. Ann. Conf. and Corrosion Show. Paper No. 547, pp: 1.

3. ISIS Canada Homepage. What is ISIS Canada?

4. Prine, D.W., 1994. Application of acoustic emission and strain gauge monitoring to steel highway bridges. Northwestern University, Evanston, Illinois, pp: 1. 
5. Huston, D.R. and F.L. Peter, 1993. Intelligent materials for intelligent structures. IEEE Communications Magazine, Oct., pp: 40-45.

6. Kersey, A.D., 1994. Monitoring of structural performance with optical TDR techniques. United States Bureau of Mines special publication SP 1994, Washington, D.C., pp: 434-442.

7. Measures, R.M., T. Alavie, R. Maaskant, M. Ohn and S. Huang, 1995. Fiber optic structural sensing for the Beddington Trail Bridge. Report submitted to ACMBS Canada.

8. Xu, M.G., H. Geiger, J.L. Archambault, L. Reekie and J.P. Dakin, 1994. Novel interrogatig system for fiber Bragg grating sensors using an acoustic-optic tunable filter. University of Southampton.
9. Measures, R.M., 1992. Smart structures- a revolution in civil engineering. Advanced composite materials in bridged and structures. Ed Neale, K.W. and Labossiere, P. Canadian Society for Civil Engineers, Montreal, Canada, pp: 31-43

10. Research Highlight, 1995. Structural control systems for buildings and bridges. The School of Engineering Quarterly, University of California, Irvine, 9: 13-14.

11. Tahir, B.A., J. Ali and R.A. Rahman, 2005. Strain measurements using fiber Bragg grating sensor, American Journal of Applied Science, Vol. 02 (special issue) pp: 40-48 